\title{
Special issue: bioremediation of contaminated soil and water: GeoTrop 2017
}

\author{
Yiu Fai Tsang $\cdot$ Yong Sik Ok $\cdot$ Ajit K. Sarmah $\cdot$ Bin Cao $\cdot$ Ming Hung Wong
}

Published online: 3 July 2018

(C) Springer Nature B.V. 2018

This special issue in Biodegradation, with a theme of Bioremediation of Contaminated Soil and Water: GeoTrop 2017, carries peer reviewed manuscripts through open calls and invitation from 20 February to 31 December 2017.

Over $40 \%$ of the land mass of the earth lies within the tropics, with almost half of the world's population. Rapid population growth, urbanization and industrialization have taken place in these areas with special environmental problems, i.e., ecotoxicology of persistent toxic substances in food production. Unfortunately, there seems to be a lack of information concerning environmental geochemistry in the tropics, compared with other parts of the world. Therefore, the

\section{Y. F. Tsang $(\varangle) \cdot$ M. H. Wong}

Department of Science and Environmental Studies, The Education University of Hong Kong, Hong Kong,

Hong Kong

e-mail: tsangyf@eduhk.hk

Y. S. Ok

Division of Environmental Science and Ecological Engineering, Korea Biochar Research Center, Korea University, Seoul, Republic of Korea

\section{A. K. Sarmah}

Department of Civil and Environmental Engineering, The University of Auckland, Auckland, New Zealand

B. Cao

Department of Civil and Environmental Engineering, Nanyang Technological University, Singapore, Singapore
International Conference on Geochemistry in the Tropics and Sub-Tropics (GeoTrop) series is to address various emerging and important environmental issues encountered in the region.

GeoTrop 2017 co-organized by Peking University Shenzhen Graduate School, The Education University of Hong Kong, and Kangwon National University, etc., was successfully held in Shenzhen, China from 8 Dec to 11 Dec 2017. This conference aimed to engage experts on the major emerging environmental issues we face as a result of rapid industrialization, while concurrently detailing the linkages between natural and disturbed chemical composition of the earth's surface, and environmental and human health, focusing on food contamination.

This special issue aims to report the latest research and development on effective biological processes currently available in treating toxic chemicals and remediating contaminated sites. The relevant topics include (1) bioremediation of contaminated soil and water; (2) advanced biological processes for the removal of environmental contamination in agricultural/horticultural/aquaculture industries; (3) biochar for sustainable waste management in agricultural/ aquaculture industries; and (4) biological waste recycling in agricultural/horticultural/aquaculture industries.

This issue fills a gap in the current lack of updated and comprehensive information about (1) the degradation of persistent toxic substances with 
unconventional treatment technologies, and (2) the management, regulation and policy concerning different toxic chemicals.

The Guest Editors are thankful to the Editor-inChief for providing an opportunity to publish this special issue. They are also thankful to the staff in the Biodegradation editorial office for their dedication in providing great assistance from the beginning to the end of the review and publication processes.
Our sincere appreciation to all the reviewers for their rigorous review of manuscripts submitted to the special issue. We look forward to meeting you soon. The 3rd International Conference on Biological Waste as Resource 2018 (BRW2018) will be held from the 17th to 19th December 2018 at The Education University of Hong Kong. 